\title{
English as a lingua franca: From classroom to out-of-class communication
}

\author{
aPelin Irgin \\ ${ }^{a}$ Asst. Prof. Dr., TED University, Turkey, pelin.irgin@tedu.edu.tr
}

APA Citation: Irgin, P. (2020). English as a lingua franca: From classroom to out-of-class communication. Focus on ELT Journal, 2(2), 4-16. https://doi.org/10.14744/felt.2020.00022

\begin{abstract}
This study explores the perceived contributions and impacts of out-of-class Keywords Language (EFL) learners' perspectives for EFL communication. Twenty-two oral communication; international and exchange students from different culture and language contexts on campus. At the onset of the process, Turkish learners were informed about the written and spoken genres of the out-of-class communication (including business meetings, job interviews, academic reports, resumes etc.) incorporated into an oral communication skill course in 14 weeks. Immediately after each ELF communication, that is the out-of-class communication activity completed with the native speakers or non-native speakers of English, they kept their weekly records and wrote self-reflections. The collected data were analyzed by following the steps of thematic analysis (Braun \& Clarke, 2006). Findings suggest that ELF-oriented practices out-of-class communication raised EFL learners' awareness and perceptions towards cultural and linguistic diversities. Also, EFL learners appeared to show new insights on intelligibility in communication and willingness to employ communication strategies such as negotiation for meaning, use of non-verbal communication, in order to enhance their intercultural communicative competence.
\end{abstract}

English as a lingua franca (ELF)-oriented practices on English as a Foreign English as a lingua franca;

Turkish EFL learners studying at a state university participated to the study and out-of-class communication; each of them were asked to engage in communication with a large number of ELF-oriented practices

(C) 2020 FELT and the Authors - Published by FELT

\section{Introduction}

In today's globalized world, English as a Lingua Franca (ELF) has emerged as a way of sociolinguistic concept referring to the contemporary use of English for communication. Since roughly one of every four users of English around the world is the native speakers of English (Crystal, 2003), the native speakers are outnumbered by non-native speakers of English, which creates a distinctive insight about ELF communication. As English is the communicative medium of choice by non-native speakers, it functions as a phenomenon for international and intercultural diversity, which is characterized by changeability, fluidity and flexibility (Cogo, 2012). With the global spread of English, "English as an international language" (EIL) (Jenkins, 2003) and "World Englishes" (Brutt-Griffler, 2002) have been used for users of English spanning Inner Circle, Outer Circle, and Expanding Circle contexts (Kachru, 1992; Seidlhofer, 2011). Within the scope of Kachru's concentric circles, EIL comprises the intranational and international communication; however, there is not a clearly captured distinction between localized EIL and globalized EIL that people can engage into 
three concentric circles: (i) inner circle - English is the first language (for example, the UK, the USA), (ii) outer circle - English is an additional language (e.g. India, Singapore), and (iii) expanding circle - English is taught and learnt as a foreign language (e.g. Turkey, China).

Despite welcomed by some culture contexts and disapproved by others, English is globally accepted as a lingua franca, which is shaped by non-native speakers as well as by native speakers of English. The consequence of the international use of English as a foreign language (EFL) creates a paradox, which refers to the dominance of native speakers on the last decision about the acceptable usage of the verbal expressions. Thus, ELF with its linguistic productivity and diversity into English language challenges native English as they are regarded as a yardstick of linguistic competence (Galloway \& Rose, 2015). In fact, Cogo's paper (2012) suggests, ELF speakers have multicompetences and effective communication strategies in contrary to the obstacles sourced from their different backgrounds.

Apart from understanding the ELF communication moving towards appreciation of cultural and linguistic diversities, it is worth considering the engagement of ELF approach to ELT practices. ELF presents language learners awareness and choice-making about different ways of speaking English (Cogo, 2012). As for the teaching of English to non-native learners, there is a need for the clarification that foreign language learning is not all about grammar, vocabulary, pronunciation but rather it is the unity of all competences for fruitful communication instead. The point here is that many researchers might regard it as the process involving both language and cultural awareness. In order to engage language teachers on ELF into their teaching practices, it is necessary to underpin the empirical research on the use of ELF and to provide ELF oriented practical applications in and out of ELT classrooms.

It is widely reported that ESL and EFL view the ultimate aim of the learners to be native-like speakers while English as a Lingua Franca (ELF) regards this aim as being able to communicate with other speakers (Whong, 2015). With the use of English for communication by the learners from different cultural backgrounds, ELF communication is driven by out of native-speaker norms. ELF scholars emphasize the need for ELF-oriented pedagogical practices incorporated into the classrooms. In designing English as a subject in ELT classes, prescriptive decisions about the aspects of language are taken, which are basically designed in connection with the objectives and processes of learning. However, the main point here is to reconsider the objectives and processes of learning that might be unreal, irrelevant and even old fashioned for the learners. The pedagogical relevance of ELF suggests an alternative way of thinking in ELT (Seidlhofer, 2011). However, very few studies (Galloway \& Rose, 2015; Sung, 2018) have empirical evidences on ELF-oriented practices and the learners' perspectives on ELF pedagogies. Thus, this study explores the perceived contributions and impacts of out-of-class ELF-oriented practices on EFL learners' perspectives for EFL communication.

\section{Awareness on ELF in ELT: Previous research}

To date, majority of the research focus on ELF at the theoretical level rather than the pedagogical implications of ELF. Bayyurt and Akcan (2015), Cogo (2012), and Sung (2015) have put forward some suggestions to expose language learners to ELF in ELT. Bayyurt and Akcan (2015) argued the value of increased exposure as English as a Lingua Franca and varies application of world Englishes in language teaching practices in multilingual and multicultural contexts. They suggested to conduct further research on the pedagogical implications for raising English teachers' awareness on how awareness on ELF can be 
implemented in a multicultural and multicultural context. Cogo (2012) suggested many researchers to approach language teaching from different perspective such as seeing language teaching more than skills, communication and knowledge. Also, he directly linked a better understanding of ELF communication drawing the attention on the appreciation on multicultural identities and diversities. Furthermore, to increase the awareness of the researchers and practitioners on ELF concept, Sung (2015) provided some suggestions on the implementation of ELF-aware approach within the classrooms. With this issue in mind, he claimed that teachers would be in a better position to prepare their learners to deal with the challenges in intercultural communication.

Galloway and Rose (2015) provided an academic rationale for the use of listening journals in ELT to raise awareness of language learners on Global Englishes. They presented pedagogical tasks to expose learners to the diversity of English in ELT, so the inclusion of various accents in ELT was a gain from learners' perspective. However, Sung (2015) discussed Galloway and Rose's finding in that it is crucial for teachers to take their students' perspectives and concerns in the ELF-adaptation process including the need for the exposure to different accents via the use of listening journals and the possible negative perceptions towards different L2 accents.

Additionally, Sung (2018) conducted a research on the implementation of an out-ofclass communication component in an ELT course in Hong Kong context to understand the impact of ELF activities on students understanding English in the global world. The students appeared to show new insights on ELF and increased their awareness of ELF. Thus, much research (Blair, 2015; Martin-Rubio \& Cots, 2018; Sifakis, 2019; Sifakis \& Bayyurt, 2018; Sung, 2018; Vettorel, 2015, 2016) suggested for further research on ELF-oriented instructional activities incorporated in ELT to have a clear understanding of learners' perspectives. As Sifakis and Bayyurt (2018) stated, if teachers become ELF-aware themselves, they can teach their learners how to be ELF-aware language users.

Dewey (2012) advocated exploring teachers' awareness in ELF in order to understand the impact of ELF in language education. In this vein, Bayyurt and Sifakis (2015) composed a model to increase awareness of teachers on ELF, and they conducted a study with inservice teachers at private and state schools in both Turkey and Greece. Based on their observations, there was a shift towards ELF- awareness in ELT. In order to change teachers' mindsets about ELF-aware approach in ELT, they offered three levels for the implementation of the ELF approach as in the following:

(1) Introducing theoretical aspects of ELF through reflective practice

(2) Preparing ELF-aware activities/lesson plans and implementing these in their classrooms

(3) Critical reflection of ELF-aware practice through the evaluation of their implementation of ELF-aware activities/lesson plans

Apparently, it is important to raise English teachers and students' awareness on the ELF and to conceptualize ELF and ELF practices in foreign language teaching and learning. The more aware teachers become about EFL in multilingual and multicultural contexts, the more aware they become towards the changing paradigms (such as linguistic and cultural diversities) in their teaching practices. Based on the citations above, there is a need to go beyond the theory-based teaching and to do deep analysis and critical reflections on ELFawareness based practices in and out of classrooms. As there has been very few research into learner's perspective into the incorporation of ELF into classroom, this study attempts to fill the void in the field. Hence, this present study aims to explore the perceived contributions 
and impacts of out-of-class ELF-oriented practices on EFL learners' perspectives for communication. This paper seeks to answer the following research questions:

1. What are the impacts of out-of-class ELF-oriented practices on leaners' perspectives for ELF communication?

2. What are the perceived impacts of out-of-class ELF-oriented practices?

\section{Methodology}

\section{Setting and participants}

The study was conducted at a state university in Turkey, which gives undergraduate education in both Turkish and English languages (some other foreign language courses optionally, as well). Beside the courses taken in the departments of the university, international office in the university presents English and Turkish classes annually for international students. The English Language Teaching and English Language and Literature students at the university were encouraged to be in communication to foster ELF communication activities, and to have an impact on both Turkish and international students' ELF conceptions. Also, the university provides education to a large number of exchange students from different European countries having Erasmus partnership.

Both national and international students undertook their courses in English at the same university campus. The international students had major courses in different faculties and field of studies of the university such as Education sciences, English language education, Engineering, Human Resources, and Economy. The university had approximately 200 international students in 2018-2019 Academic year and they were participating the meetings organized by the international office of the university in order to increase their awareness on Turkish culture context and to present their own culture to the students from other cultures.

An elective oral communication course covered by the researcher in an academic semester at the university was designed to improve EFL learners' use of spoken English in a variety of communication-oriented activities that require clarity of expression and critical assessment on cultural and linguistic diversities, and to develop awareness on global Englishes.

Twenty-two students enrolled on the oral communication course were foreign language learners of English studying at the English language and literature department, whose English proficiency level ranged from upper-intermediate to advanced levels tested via Pearson English Language Test (PTE) for academic purposes. The students had very limited opportunities to practice ELF communication in the classroom setting as there are almost two or three exchange students in their classes every academic term. The classroom language was English but Turkish students had high potential to use their L1 in and out of the classroom. Rather than engaging in ELF communication with the exchange students in the department, they were using Turkish language for oral interaction in order to teach them Turkish language. Based on the researcher's observation, it was seen that Turkish students had some ambivalent attitudes towards the different accents and hesitations on how to deal with communication breakdowns by reason of different accents in practice. Therefore, the content of the oral communication course was designed to encourage and do actually out of class ELF communication with international and exchange students from different language and culture backgrounds. 
Table 1. The weekly course content

\begin{tabular}{|c|c|c|}
\hline Weeks & Topics & Skills \& Objectives \\
\hline 1 & $\begin{array}{l}\text { Introduction to the course } \\
\text { syllabus, } \\
\text { Getting to know each other, } \\
\text { setting expectations, English as a } \\
\text { Lingua Franca (ELF), Self- } \\
\text { reflection paper writing }\end{array}$ & $\begin{array}{l}\text {-Introducing the course syllabus - } \\
\text { Presenting guideline on how to write self- } \\
\text { reflection }\end{array}$ \\
\hline 2 & Small Talk & $\begin{array}{l}\text {-Initiating \& maintaining a conversation } \\
\text { on safe topics in different situations }\end{array}$ \\
\hline 3 & Expressing opinions \& debating & -Expressing opinions and debating skills \\
\hline 4 & Academic oral presentations skills & $\begin{array}{l}\text {-Delivering \& reflecting on academic } \\
\text { presentations } \\
\text {-Expanding collocation \& vocabulary }\end{array}$ \\
\hline 5 & Interviews \& Job talks & $\begin{array}{l}\text {-Practicing skills of conducting \& } \\
\text { participating in interviews }\end{array}$ \\
\hline 6 & Culture: manners and politeness & $\begin{array}{l}\text {-Inter-cultural awareness on politeness and } \\
\text { manners } \\
\text {-Expressing social communicative } \\
\text { functions }\end{array}$ \\
\hline 7 & Mid-term Exam & \\
\hline 8 & Health issues & $\begin{array}{l}\text {-Practice medical language } \\
\text {-Pronunciation of problematic medical } \\
\text { words }\end{array}$ \\
\hline 9 & $\begin{array}{l}\text { World Politics and Religious } \\
\text { issues }\end{array}$ & $\begin{array}{l}\text {-Practice discussing controversial political } \\
\text { and religious issues }\end{array}$ \\
\hline 10 & News \& Current Affairs & $\begin{array}{l}\text {-Understanding radio and TV news \& } \\
\text { documentaries } \\
\text {-Debating and argumentation skills }\end{array}$ \\
\hline 11 & Language \& literature & $\begin{array}{l}\text {-Discussing Language and literary issues } \\
\text {-Retelling stories } \\
\text {-Understanding American and British } \\
\text { English }\end{array}$ \\
\hline 12 & World Englishes \& Accents & $\begin{array}{l}\text {-Discussing World English and English: } \\
\text { Local accents and global accents }\end{array}$ \\
\hline $\begin{array}{l}13 \\
14\end{array}$ & $\begin{array}{l}\text { Charity \& voluntary works } \\
\text { Final Exam }\end{array}$ & -Discussing charity and voluntary works \\
\hline
\end{tabular}

They were informed about taking notes about time, setting, interlocutor(s)' background, and purpose of the oral communication (see Figure 1). Also, they were expected to write their self-reflections following the instructor's guideline on how to write their reflections (see Figure 2). Based on the weekly tentative course syllabus illustrated in Table 1, the participants were expected to practice on the relevant topic and write down their reports and self-reflection papers after each weekly topic was covered in the class. Then, they implemented the out-of-class communication, English as a Lingua Franca (ELF) practices with the international students at the university campus taking nearly 30 minutes talks each week. Later, the participants wrote their weekly reports and self-reflection papers 
in English. Eleven weekly reports and reflection papers was gathered from each participant during the academic term.

Then, the students were directed to participate to the meetings of the international office to perform their weekly out-of-class communication. Immediately after each ELF communication, that is the out-of-class communication activity completed with the native speakers or non-native speakers of English, they kept their weekly records and wrote selfreflections to submit them to the instructor. The students could respond to each item/question in their self-reflections and reports.

\begin{tabular}{|c|c|}
\hline Pseudo name & \\
\hline Week & $\begin{array}{llllllllllllll}1 & 2 & 3 & 4 & 5 & 6 & 7 & 8 & 9 & 10 & 11 & 12 & 13 & 14\end{array}$ \\
\hline \multicolumn{2}{|r|}{ 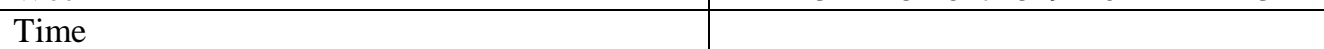 } \\
\hline \multicolumn{2}{|l|}{ Duration } \\
\hline \multicolumn{2}{|l|}{ Place } \\
\hline \multicolumn{2}{|l|}{$\begin{array}{l}\text { Interlocutor(s)' native language and } \\
\text { nationality }\end{array}$} \\
\hline \multicolumn{2}{|l|}{1} \\
\hline \multicolumn{2}{|l|}{2} \\
\hline \multicolumn{2}{|l|}{3} \\
\hline \multicolumn{2}{|l|}{4} \\
\hline \multicolumn{2}{|l|}{ Oral communication } \\
\hline \multicolumn{2}{|l|}{ Topic } \\
\hline 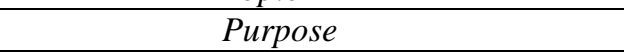 & \\
\hline $\begin{array}{l}\text { Personal notes (Observations on linguistic features, } \\
\text { communication breakdowns, oral communication } \\
\text { strategies, etc.) }\end{array}$ & \\
\hline
\end{tabular}

Figure 1. Template for students' weekly records

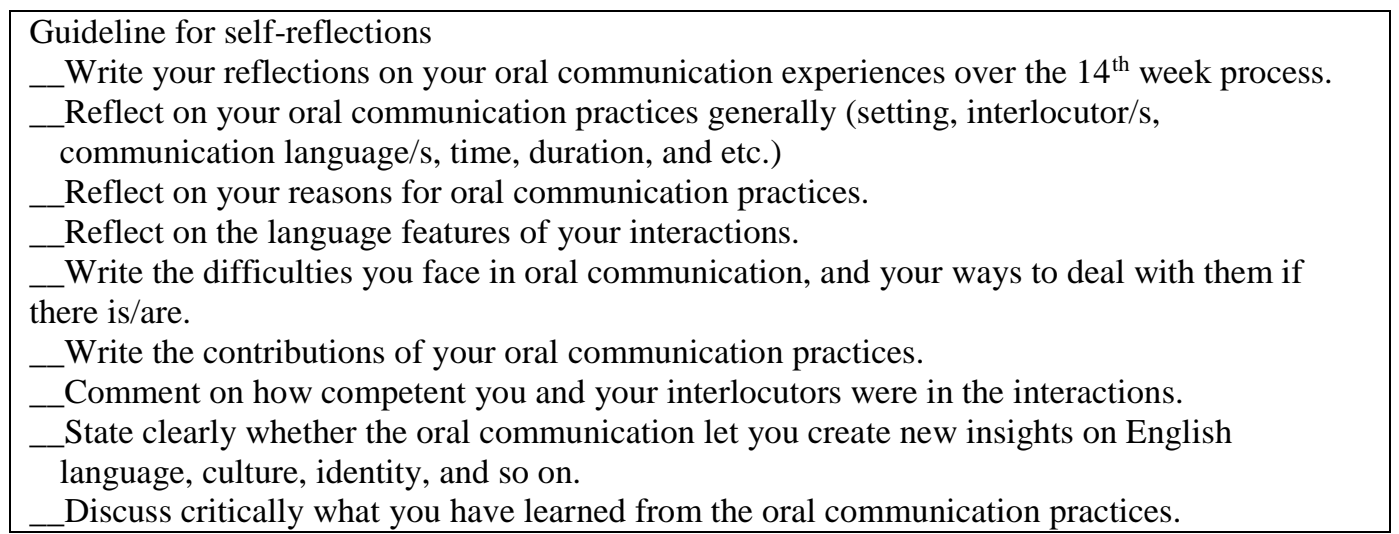
Figure 2. Instructor's guideline for students' self-reflections

The collected data was analyzed by following the phases of a thematic analysis as described by Braun and Clarke (2006). Students' weekly written reflections were reviewed and the themes emerged from the students' written extracts were identified. The process of data analysis gradually changed from mainly inductive to become more deductive. As the thematic analysis is not tied to a particular theoretical framework within a qualitative paradigm, it could be conducted in a critically realist, contextualist and constructionist theoretical perspective. 
Table 2. Braun and Clarke's (2006) six-phase inductive thematic analysis

\begin{tabular}{lll}
\hline Phases & Description of the process \\
\hline $\begin{array}{l}\text { 1. Familiarizing yourself with your } \\
\text { data }\end{array}$ & $\begin{array}{l}\text { Transcribing data, reading and re-reading the } \\
\text { data, noting down the initial ideas. }\end{array}$ \\
2. Generating initial codes & $\begin{array}{l}\text { Coding interesting features of the data in a } \\
\text { systematic fashion across the entire data set, } \\
\text { collating data relevant to each code. } \\
\text { Gathering data and collating codes into } \\
\text { potential themes. } \\
\text { Checking the themes in relation to the coded } \\
\text { extracts and the entire data set, generating a } \\
\text { thematic "map" of the analysis. } \\
\text { Ongoing analysis to refine each theme and } \\
\text { generate clear definitions and names for each } \\
\text { theme. } \\
\text { Selection of vivid, compelling text extracts } \\
\text { relating to the analysis to the research question } \\
\text { and literature, producing a scholarly report. }\end{array}$ \\
\end{tabular}

The author and one independent researcher having experience in transcribing and analyzing qualitative data including deductive and inductive coding, coded and analyzed the data in order to ensure inter-rater reliability. The data reported in the student reflections were coded by both researchers independently and then compared with the codes of the other researcher. The inter-coding and intra-coding included checking the segmentation and coding of the data. The statistical similarity analysis of coding revealed very high agreement between two coders $(.91, p<.001)$ as over .80 values represent very high agreement (Landis $\&$ Koch, 1977). Any disagreements in coding were resolved through discussion.

\section{Results}

Based on the EFL learners' weekly reports and self-reflections on their out-of-class communication activities, the findings reveal the impacts of ELF-oriented pedagogical practices incorporated in the classroom and splashed out-of-class communication on EFL learners' ELF perspectives. Four main impacts of EFL students' oral communications on the conceptions of English in the global context were identified from the collected data. What the perceived impacts of out-of-class ELF-oriented practices were and how they contributed to EFL learners were presented as below;

(1) raising EFL learners' awareness and perceptions towards cultural and linguistic diversities

(2) showing new insights on intelligibility in communication

(3) showing willingness to employ communication strategies such as negotiation for meaning, use of non-verbal communication

(4) enhancing their intercultural communicative competence.

Theme 1: Awareness on cultural and linguistic diversities

One of the four main impacts identified in the EFL students' reflections is awareness on cultural and linguistic diversity of English in ELF-oriented communication. The reports of the students reflected that EFL students perceived the language and culture variations in 
their out of class practices with native and non-native speakers of English, and showed an increased tolerance for cultural and linguistic differences. One student in her self-reflection paper, for example, wrote: "Rather than alienating people from each, we should be respectful for the differences because we
all live in the same world and English is the global language to communicate with people from
different cultures." (St2)

Another student noted about their increased awareness stating as below:

“.......I realize the changes in my thoughts about other non-native speakers of English. I used to judge people when they speak English out of American or British accent. I know this is not nice. I know that I do not have very good accent, but I start to pay attention to correct pronunciation of the words, word stress, intonation, and etc. Personally, I am now more respectful for different accents, and I have more acceptance of cultural diversities, as well." (St5)

Even though the students seem ready for linguistic differences and cultural diversities in classroom environment, the natural dynamics of oral communication with interlocutors from diverse culture contexts revealed some concerns such as communication breakdowns. However, it was seen that students had disposition to increase their awareness on the cultural and linguistic diversities. For instance, one of the students wrote in her self-reflection paper:

"We live in the same world but we have lots of differences. Our colors, culture, country, and language differentiate from one another. I know that English is the global language and there are some variations in language, which I appreciate it a lot. I cannot imagine a world where people speak English with the same accent." (St11)

Similarly, one another reflected on cultural diversities in his self-reflection paper:

"I have always thought that to communicate with native speakers of English are better than the non-natives to improve my English language skills. But, now I think that it is nonsense to categorize people in that way, and even to question which one is better. ....Thanks to people from different cultures I could have some ideas about their countries, life, music, food, and I could learn some words in their native language." (St18)

This quotation indicates that students might be aware of both linguistic and cultural diversities when they are presented opportunities to use English out of classroom ELF practices. They appear to assess themselves regarding the cultural and linguistic components in both national and global settings, and to enlarge their viewpoints towards variations of English.

\section{Theme 2: New insights on intelligibility in communication}

The gradually growing body of this research leads to a better understanding on the nature of ELF, more specifically new insight on intelligibility in communication. In language teaching process, linguistic features potentially tend to be for learners in international settings, which are distinguished from the standard features of language (Seidlhofer, 2011). Thus, the new focus basically can be on intelligible use of language, rather than striving for the nuances of native speaker or native like speakers' language use. For example, the students indicated their relevance on the intelligible use of language by keeping the native-speaker norms at the center of ELF communication, especially with respect to interlocutors' pronunciation and fluent English, as evidenced in the self-reflection papers of Student 13 and Student 21: 
"It is important to me not to restrict myself with the boundaries of native-speakers' language norms. I started to think that there is no limitation in communication as long as people ensure intelligibility in their conversations." (St13)

"It would be tedious if we all speak with the same accent. I cannot even imagine my international friends start to use English with the same or similar way. It is not necessary to have the same British or American accent. As long as I understand what they mean, there is no problem to have different accents. I like the way they speak." (St21)

It should be highlighted that linguistic descriptions of languages are nor prerequisite for being informed about language, neither enough for purposeful language usage. It provides necessary information just for particular settings but learners might be in need of more productive solutions in lingua franca settings.

\section{Theme 3: Willingness to employ oral-communication strategies}

The findings of this study is in more agreement with that of Borghetti and Beaven (2015), who point out the contributions of ELF setting on non-native speakers of English such as experiencing lower level of embarrassment, fear of being judged on language skills, and worrying about participating in interaction. Also, in a similar vein, the participants of this study claimed that they perceived a higher level of negotiation for meaning and communication strategies in an ELF setting, which leads them to engage in more interaction with speakers of other languages and native speakers. Also, students indicated their willingness to employ communication strategies such as getting the gist of the speech, the use of body language, filling the gaps in meaning, and adapting to the communicative requirements, as shown in the following extracts from their weekly reports and selfreflection papers:

"I feel that I have improved my communication skills...now I know better what to say in the correct time." (St12)

"I use my gestures and mimics while speaking with speakers of other languages. I think it helps me a lot to express my ideas accurately." (St22)

"Sometimes, I notice the breakdowns in the communication with native and non-native speakers. Native speakers usually speak very fast and they might have very strong accent. When I could not catch what they mean, I kindly request to repeat and slow down to continue our communication." (St14)

As referred from the extracts above, the students have efforts to continue meaningful ELF communication by using communication strategies, rather than deterring from the conversation or stopping the conversation. They show willingness to communicate and challenge with the points needed to be improved. Of significance is these students reflect some adaptive accommodation strategies in the very natural ELF setting.

\section{Theme 4: Enhancing intercultural communicative competence}

Based on the analysis of students' written reflections, twenty of them were able to participate in international English communication and had self-confidence to communicate with people from other positions. Almost all students could demonstrate interactional skills such as negotiating, repairing, opening and closing conversations in their ELF-oriented oral communications from different culture contexts. They could use both formal and informal 
vocabulary including figurative language and idiomatic usage of ELF English. They developed rhetorical speaking and critical thinking skills, an understanding of phonetics as one of the core elements in English, and an increased fluency in varieties of ELF. They could build confidence in terms of using ELF appropriately in the critical analysis of others' speeches and the delivery of group and individual speeches in out-of-class communication. They could speak with sufficient accuracy and fluency to facilitate comprehension in professional and academic genres as they had been informed about the written and spoken genres in their course. They could participate in ELF-oriented oral communication by explaining and supporting their opinions with high self-confidence.

As evidenced in the written reflections, the students emphasized their efforts to continue ELF communication with interlocutors from diverse L1 backgrounds. Their reflections show that they start to have a new notion of communicative competence with the social milieu of the native and non-native speakers of English. For example, two students wrote:

\footnotetext{
"Out of classroom ELF practices contributed me a lot. Now I know more about African culture. Even I have started to enjoy listening to African music. It is now easy for me to communicate in English with people from abroad. Especially, music culture might be a reason for communication." (St17)

"Now, interestingly I can adapt to communication with people from different backgrounds. Before, I used to hesitate to communicate, and I was a bit shy but now I start to trust myself, and my English...I believe that wherever they come from, I have self-confidence to communicate in any international setting." (St10)
}

In addition, one student stated the importance of teaching students how to communicate in international and intercultural settings. He stated: "I think teachers should integrate more ELF practices into oral communication courses. I improved my communication skills by talking with other speakers of English, and learned a lot from their culture, experience and lifestyle." As reported here, oral communication courses at language department might be an impulse to increase EFL students' awareness on ELF communication and intercultural communicative competence. However, opportunities to interact with speakers of other languages should be presented. In cases the ELF context could not be possible in the same learning environment, it is inevitable to enrich courses via technologies for distance communication such as webinars, teleconferencing or videoconferencing and so on.

The students increased their awareness on ELF communication and internalized the importance of employing effective intercultural communication strategies in English. They improved their both listening and speaking (oral communication) skills and strategies. They also improved their pronunciation skills with special emphasis on the effective analysis of language input. They employed an appropriate and effective range of verbal and non-verbal skills in a variety of ELF practices.

\section{Discussion}

It has been established in the findings of the research that the ELF-oriented practices out-ofclassroom communication have impact on EFL learners' raising awareness towards cultural and linguistic diversities, getting new insights on intelligibility in communication, showing willingness to employ communication strategies, and enhancing international communicative competence. As a result of the out-of-classroom activities, the students 
experienced and assessed their own performance in using English in a real setting enriched and associated with ELF.

As evidenced in the students' reflections, the findings of this research suggest that there is a connection between engaging in ELF oriented practices out of classroom communication and raising awareness of ELF, which was perceived to be beneficial personally and pedagogically. This is most probably because of the positive outcomes rising from the pedagogical concept of ELF. In the light of the out-of-classroom communication practices, the students increased their willingness to communicate and their awareness on the role of world English. Besides the explicit instruction of ELF in the classroom, the outof-classroom practices might have high potential to increase awareness of students on ELF as they have direct and very active exposure to the authentic ELF communication in their natural setting. The ELF scenarios created for the students from the same or very similar cultural and linguistic backgrounds might be a limitation to experience linguistic and cultural diversities. Thus, the out-of-classroom ELF dynamics might present new opportunities and dimensions, and foster the understanding upon ELF communication. In that sense, it is important to implement out-of-classroom ELF communication for the classroom settings where opportunities to communicate with speakers of other languages is very rare. Similarly, the findings of this research support Martin-Rubio and Cots (2018)' s study that students not only gain fluency with their English in an ELF setting which seems to be connected with the participation to the in and out of class discussions, but they also perceive a greater level of accommodation, cooperation and negotiation strategies in their communication with non-native speakers of English.

Moreover, it is worth to point out the importance of written reflections to explore students' critical thinking on ELF and communicative practices structured on ELF. EFL learners in this research appeared to show new insights on intelligibility in communication and willingness to employ communication strategies such as negotiation for meaning, use of non-verbal communication, in order to enhance their international communicative competence. All of these components can be result of having deeper reflections and metacognition on their own ELF communication experiences. Based on the framed topics on ELF communication, students could explore possible options for enhancing their intercultural communicative competences, and develop their decision making on communication breakdowns in an ELF setting. At this point, Llurda (2016) notes that it has been important to change the students' mindset on the scope of ELF, self-awareness, selfconfidence and identity development. As EFL learners in this research explicitly informed and instructed about the different genres, it was seen that the explicit instruction of genres might have influence on the students' perceptions on ELF communication. Furthermore, the implementation of pedagogical activities on ELF could prompt students to develop deeper insight and awareness on ELF. To take a further step from this suggestion, foreign language teachers can be urged for the teaching of English as a Lingua Franca besides teaching English about grammar, vocabulary, pronunciation and a set of skills.

While the reflection tasks allowed the students enlarge their viewpoints and awareness on ELF, they supplied students some contributions to make decisions on what kind of English they would prefer to use for intercultural communication and how they would cope with the possible problems in ELF communication. It is important to note here that written reflections could allow students explore the notion of ELF framed on their own communication experiences (Cogo, 2012). The students in this study could appreciate what communication means in an ELF setting and how students structure their intercultural communicative competences via their ELF practices. This study reporting the effective 
outcomes of out-of-classroom ELF communication component implies for further research to compare students' critical thinking on ELF. Therefore, further research could be effective for non-native speakers of English to raise their awareness and understanding on ELF communication.

\section{Conclusion}

In this study, it is examined to explore the perceived contributions and impacts of out-ofclass ELF-oriented practices on EFL learners' perspectives for communication. It seems clear from the results of this study that the implementation of out-of-classroom ELF practices in an ELT course such as oral communication could be motivating to create awareness on ELF and to encourage engagement in ELF communication. Particularly, this experiential ELF-oriented study not only implies the positive effects of implementation outof-classroom communication component as practical implications, but it also suggests explicit teaching of ELF in the classroom as a part of course content as it was confirmed in Bayyurt and Akcan's (2015) study. Hence, this study has presented methodological contributions and practical implications to understand impacts of out of classroom practices on students' perceptions for ELF communication.

This study is just for a starting point for further exploration of out of classroom ELF practices and ELF awareness in an ELT context. In Turkish context, the ELF environment which was very welcoming for international students from various linguistic and cultural backgrounds, offered valuable opportunities to view English in the global context rather than limiting the use of English merely in an oral communication course.

Therefore, it is important to conduct further studies in EFL contexts to accommodate the case of English as a means of intercultural and international communication. Language teachers should develop target language communicative competence in EFL learners by integrating out of classroom ELF tasks into their courses. The intercultural communicative competence of the EFL learners should be developed by equipping them cultural and linguistic behaviors to have effective ELF communication. ELF-oriented pedagogical out of classroom practices should involve both national and international norms which are relevant to learners' lives. Instructional materials and activities should have suitable discourse samples pertaining to native and nonnative speaker interactions, as well as nonnative and nonnative speaker interactions.

\section{Disclosure Statement}

No potential conflict of interest was reported by the author.

\section{References}

Bayyurt, Y., \& Akcan, S. (2015). Current Perspectives on Pedagogy for English as a Lingua Franca. De Gruyter Mouton. https://doi.org/10.1515/9783110335965

Bayyurt, Y., \& Sifakis, N. C. (2015). Developing an ELF-aware pedagogy: Insights from a self-education programme. In P. Vettorel (ed.), New Frontiers in Teaching and Learning English (pp. 55-76). Cambridge Scholars Publishing.

Blair, A. (2015). Evolving a post-native, multilingual model for ELF-aware teacher education. In Y. Bayyurt, \& S. Akcan (Eds.), Current perspectives on pedagogy for English as a lingua franca (pp. 89-102). De Gruyter. https://doi.org/10.1515/9783110335965.89

Borghetti, C., \& Beaven, A. (2015). Lingua francas and learning mobility: Reflections on students' attitudes and beliefs towards language learning and use. International Journal of Applied Linguistics, 27(1), 221-241. https://doi.org/10.1111/ijal.12123

Braun, V., \& Clarke, V. (2006). Using thematic analysis in psychology. Qualitative Research in Psychology, 3(2), 77-101. https://doi.org/10.1191/1478088706qp063oa 
Brutt-Griffler, J. (2002). World English. A Study of its Development. Multilingual Matters. https://doi.org/10.21832/9781853595790

Cogo, A. (2012). English as a Lingua Franca: concepts, use and implications. ELT Journal, 66(1), 97-105. https://doi.org/10.1093/elt/ccr069

Crystal, D. (2003). English as a Global Language. Cambridge University Press.

Dewey, M. (2012). Towards a post normative approach: Learning the pedagogy of ELF. Journal of English as a Lingua Franca, 1(1), 141-170. https://doi.org/10.1515/jelf-2012-0007

Galloway, N., \& Rose, H. (2015). Introducing Global Englishes. Routledge.

Jenkins, J. (2003). World Englishes. Routledge.

Kachru, B. (1992). The Other Tongue: English across Cultures. University of Illinois Press.

Landis, J. R., \& Koch, G. G. (1977). The measurement f observer agreement for categorical data. Biometrics, 33(1), 159-174. https://doi.org/10.2307/2529310

Llurda, E. (2016). "Native Speakers", English and ELT: changing perspectives. In G. Hall (ed.), The Routledge Handbook of English Language Teaching (pp. 69-81). Routledge.

Martin-Rubio, X., \& Cots, J. M. (2018). Self-confidence amongst study abroad students in an "English as a lingua franca" university. Language Awareness, 27(1-2), 96-112. https://doi.org/10.1080/09658416.2018.1435673

Seidlhofer, B. (2011). Understanding English as a Lingua Franca. Oxford University Press.

Sifakis, N. C. (2019). ELF awareness in English Language Teaching: Principles and Processes. Applied Linguistics, 40(2), 288-306. https://doi.org/10.1093/applin/amx034

Sifakis, N. C., \& Bayyurt, Y. (2018). ELF-aware teaching, learning and teacher development. In J, Jenkins, W. Baker, \& M. Dewey (Eds.), Handbook of English as a Lingua Franca (pp.456-467). Routledge. https://doi.org/10.4324/9781315717173-37

Sung, C. C. M. (2015). Exposing learners to global Englishes in ELT: some suggestions. ELT Journal, 69(2), 198-201. https://doi.org/10.1093/elt/ccu064

Sung, C. C. M. (2018). Out-of-class communication and awareness of English as a Lingua Franca. ELT Journal, 72(1), 15-25. https://doi.org/10.1093/elt/ccx024

Vettorel, P. (2015). World Englishes and English as a Lingua Franca: Implications for teacher education and ELT. Iperstoria, 6, 229-244.

Vettorel, P. (2016). WE-and ELF-informed classroom practices: Proposals from a pre-service teacher education programme in Italy. Journal of English as a Lingua Franca, 5(1), 107-133. https://doi.org/10.1515/jelf-2016-0005

Whong, M. (2015). Language Teaching: Linguistic Theory in Practice. Edinburgh University Press.

\section{Copyrights}

Copyright for this article is retained by the author(s), with first publication rights granted to the Journal.

This is an open-access article distributed under the terms and conditions of the Creative Commons Attribution license (CC BY-NC-ND) (http://creativecommons.org/licenses/by-nc-nd/4.0/). 